\title{
Cultura sexual, ciência e política: uma entrevista com Richard Parker
}

\author{
Sexual culture, science, and politics: \\ an interview with Richard Parker
}

Regina Maria Barbosa 1

Estela Maria Leão de Aquino 2

\footnotetext{
1 Núcleo de Estudos de População, Universidade Estadual de Campinas. Rua Albert Einstein $s / n$ Cidade Universitária, Campinas, $S P$ 13083-970, Brasil. rbarbosa@nepo.unicamp.br 2 MUSA - Programa de Estudos em Gênero e Saúde, Instituto de Saúde Coletiva, Universidade Federal da Bahia. Rua Padre Feijó 29, 4 o andar, Salvador, $B A$ 40110-170, Brasil. musa@ufba.br
}

A constituição e a consolidação do campo de estudos sobre sexualidade, gênero e saúde no Brasil, nas últimas duas décadas, se confundem com a trajetória profissional de Richard Guy Parker, tanto por sua defesa firme da pesquisa e do ensino nesse campo, como por sua militância apaixonada na área dos direitos humanos, sexualidade e AIDS.

Esta entrevista 1 é ao mesmo tempo uma forma de agradecer e reconhecer o trabalho desse brilhante intelectual que, nascido acima da linha do Equador - fazendo aqui referência a um de seus livros mais conhecidos 2 -, tem sido um parceiro incansável nas lutas em prol de uma sociedade mais democrática, diversa e plural.

Richard Parker nasceu em 1957, no Estado de Wisconsin, Estados Unidos. Obteve graduação em Antropologia, em 1980, e doutorado em Antropologia, em 1988, na Universidade da Califórnia (UC), Berkeley, Estados Unidos. Em 1990, fez seu pós-doutorado na Universidade Federal do Rio de Janeiro (UFRJ), Rio de Janeiro, Brasil, como bolsista do Social Science Research Council.

Em 1983, veio ao Brasil com o propósito de realizar um estudo sobre cultura e poder, tendo o carnaval carioca como campo etnográfico. Fascinado com a força da sexualidade nessa festa popular, redefiniu seu objeto de investigação, produzindo um trabalho que se tornou referência obrigatória para quem investiga o tema no Brasil. Posteriormente, sob o impacto da emergência da AIDS, buscou articular essas duas questões.

Atualmente é professor titular e chefe do Department of Sociomedical Sciences e diretor do Center for Gender, Sexuality and Health na Mailman School of Public Health da Universidade de Colúmbia em Nova York, e também professor no Instituto de Medicina Social (IMS) da Universidade do Estado do Rio de Janeiro (UERJ), de onde se encontra licenciado.

A ênfase na articulação entre a produção acadêmica e a formulação de políticas, investindo em uma interlocução permanente entre academia, Estado e sociedade, é sem dúvida uma marca na trajetória profissional de Richard Parker, que sempre buscou promover espaços criati- 
vos e pouco usuais de diálogo entre essas instâncias. Assim, durante a última década, além de seu trabalho acadêmico, também participou de várias comissões e ocupou uma série de cargos em instituições governamentais e não-governamentais. De 1991 a 1996, foi coordenador do AIDS and Reproductive Health Network's Working Group on Sexual Behavior Research e, de 1994 a 1995, membro do Steering Committee de Pesquisa Social e Comportamental, no Programa Global de AIDS da Organização Mundial da Saúde (OMS). Em 1992, foi chefe da Unidade de Prevenção do Programa Nacional de AIDS. De 1993 a 1996, pertenceu ao Comitê Nacional de Pesquisa de Vacina de HIV/AIDS, e de 2000 a 2003, foi membro do Comitê Nacional de Pesquisa em HIV/AIDS, do Ministério da Saúde (MS). De 1992 a 1995, foi coordenador-geral da Associação Brasileira Interdisciplinar de AIDS (ABIA). Em 1995, deixou o cargo para se tornar secretário-geral dessa mesma instituição, da qual se tornou presidente em 1998. Desde 1994 é membro da Comissão de Cidadania e Reprodução (CCR) e compõe atualmente o conselho diretor da ADVOCACI, organização não-governamental sediada no Rio de Janeiro, do ICASO (International Council of AIDS Service Organizations), em Toronto 1 e do Institute for Gay Men's Health Crisis (GMHC), em Nova York.

Entre as dezenas de publicações de sua autoria - livros, capítulos de livros e artigos científicos sobre o tema-destacam-se as obras: Corpos, Prazeres e Paixões: Cultura Sexual no Brasil Contemporâneo (1991) 2; Na Contramão da AIDS: Sexualidade, Intervenção, Política (2000) 3 e Abaixo do Equador: Culturas de Desejo, Homossexualidade Masculina, e Comunidade Gay no Brasil (2002) 4.

No início da década de 90, Richard criou, no IMS, o Programa de Estudos em Sexualidade, Gênero e Saúde, iniciativa pioneira que promoveu, além de uma série de pesquisas, vários treinamentos curtos e seminários relativos ao tema. A partir de 1996 tornou-se claro que essa experiência deveria ser ampliada, de forma mais sistemática e incisiva, na formação de jovens pesquisadores e na produção de conhecimento científico de qualidade nessa área. Naquela ocasião, estava sendo concebido pelas editoras deste suplemento o Programa Interinstitucional de Treinamento em Metodologia de Pesquisa em Gênero, Sexualidade e Saúde Reprodutiva. Proposta que Richard Parker ajudou a viabilizar ao construir as condições materiais e políticas necessárias para sua concretização, por intermédio do apoio da Fundação Ford, embora, naquele momento, ele já estivesse com data marcada para voltar aos Estados Unidos.

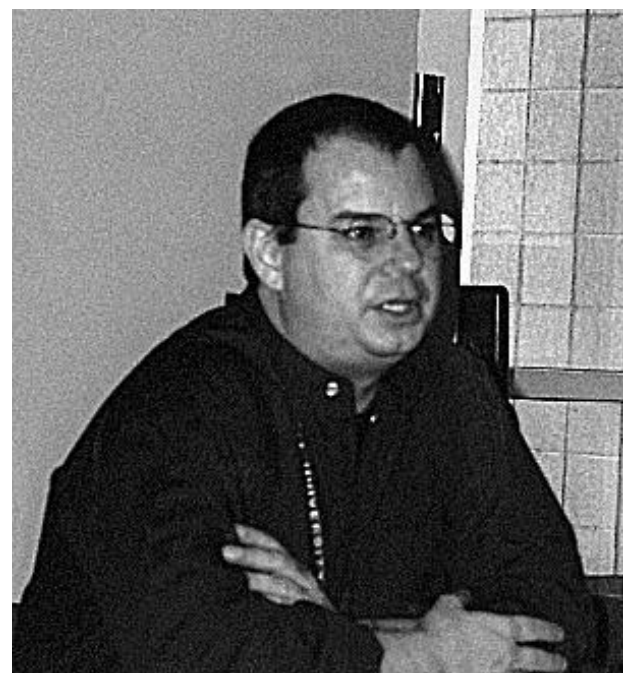


Regina Barbosa Para começar, gostaríamos de recuperar um pouco a história dos estudos sobre sexualidade através da sua biografia e a maneira pela qual você se inseriu nesse campo. Richard Parker Num primeiro momento, minha trajetória esteve relacionada com o próprio contexto político e cultural em que nasci e cresci, nos Estados Unidos. De certa forma, sou herdeiro dos anos 60, das mudanças sociais desse período. Herdei também a atração pela Antropologia, ciência que, em termos disciplinares, confere importância e propicia um encontro com a diversidade humana por meio das diferenças culturais. Graduei-me em Antropologia na UC Berkeley, e fiz mestrado e doutorado na mesma instituição. Foi nessa época que meu encontro com o Brasil começou a se configurar. No final dos anos 70 e início dos 80 , as ciências sociais experimentaram um certo declínio. Após uma grande expansão durante os anos 60 , houve uma contração orçamentária, e ficou muito difícil conseguir trabalho nos Estados Unidos. As oportunidades de trabalho eram muito maiores se envolvessem pesquisa em contextos exóticos; assim, o melhor para um antropólogo seria trabalhar com uma tribo indígena, numa aldeia longínqua. Mas eu também reconheci, muito rapidamente, que a selva teria de ser urbana. Na época eu já tinha interesse pelo Brasil e, como não falava o idioma - eu conhecia o espanhol -, pensei que poderia aprender português no próprio país. Passei dois meses aqui e gostei muito de uma série de aspectos da cultura brasileira, as quais considerei atraentes e interessantes. Resolvi então ficar para fazer a pesquisa de doutorado. No início, todo o meu interesse centrava-se na vinculação entre cultura e política, especialmente no modo como a cultura é manipulada politicamente, como o poder funciona dentro da cultura. Não tinha a intenção de estudar sexualidade, queria estudar a construção política da cultura. A idéia era fazer uma pesquisa sobre a manipulação do carnaval, um estudo histórico sobre como essa festa popular é transformada, em certo sentido, numa festa domesticada - em síntese, mostrar de que maneira a cultura popular é apropriada pelos políticos e transformada em um projeto de poder. Foi uma época ótima para desenvolver esse estudo, já que a construção do Sambódromo 5 no Rio de Janeiro estava em pleno andamento, fato que, simbolicamente, consistia exatamente nisso: colocar os pobres do morro num espaço controlado pelo Estado. Havia, portanto, um clima bastante rico para essa discussão, e esse foi o propósito da minha vinda para o Brasil. No entanto, quando comecei a pesquisa, percebia a sexualidade surgindo em todos os momentos. Quando falava com as pessoas sobre o carnaval, quando olhava as imagens, as representações, ficava cada vez mais evidente que o carnaval estava relacionado com a construção da sexualidade. E foi realmente nesse contexto, em 1983, que o projeto de pesquisa sobre o carnaval transformou-se em um estudo sobre sexualidade, ficando o carnaval restrito a um único capítulo desse trabalho mais amplo. Outra coisa que ocorreu na época foi a emergência da AIDS. Em 1981, registrou-se o primeiro caso da doença nos Estados Unidos, e em 1982, na minha primeira vinda ao Brasil, houve aqui o primeiro caso declarado 6. Quando voltei para fazer o trabalho de campo, no ano seguinte, o debate sobre a questão da AIDS atingia seu auge nos Estados Unidos. Em São Francisco, na comunidade gay, as pessoas estavam morrendo. Não se passava um dia sem se falar sobre AIDS. Aqui, no entanto, embora a AIDS já estivesse presente, ninguém tocava no assunto. Não se viam reportagens nos jornais e, quando saía alguma coisa, era sobre São Francisco ou Nova York. Ainda não havia o registro dela no imaginário brasileiro. Então, para mim, se colocava a junção da sexualidade evidente no carnaval e a AIDS como pano de fundo, mas de uma forma ainda muito pouco conhecida e articulada.

RB De que maneira se dá a relação entre carnaval, sexualidade e AIDS no contexto brasileiro? Se você pudesse, talvez, pesquisar carnaval num outro país, por exemplo, da América do Sul ou América Central...

RP Absolutamente não. Muitos países comemoram o carnaval, mas em nenhum outro o carnaval e o imaginário sexual que nele se produz e reproduz é tão vinculado à própria identidade cultural, à brasilidade, em um certo sentido. No primeiro livro que publiquei, Corpos, Prazeres e Paixões... 3 , tento analisar essa relação. De certa forma, ao menos simbolicamente, a interação sexual chega a ser quase uma metáfora, pela própria formação do povo brasileiro. Poucas sociedades conferem essa importância à sexualidade em termos de identidade cultural. Em outros lugares essa dimensão não teria emergido com a força que teve no Brasil. Mas isso não foi previsto ou antecipado, ou seja, não vim com a intenção de investigar a partir dessa perspectiva. Fui descobrindo aqui. Terminei a primeira etapa da pesquisa em 1984 e voltei para os Estados Unidos. Lá a questão da AIDS estava ainda mais explosiva. Se antes eu só conhecia à distância as pessoas que morriam, naquele momento eu as conhecia pessoalmente. O impacto foi muito grande porque 
no Brasil a AIDS ainda permanecia como um tema não muito explorado. Foi então que realmente tentei analisar a "cultura sexual" no Brasil em termos do que ela tinha a dizer sobre o caminho da epidemia e prever seus desdobramentos. Certamente, a idéia de que a epidemia aqui ficaria muito menos restrita a uma comunidade gay fechada, pela maneira como as relações homo e bissexuais se dão no país, foi um dos aspectos mais evidentes. Num sentido mais amplo, comecei a refletir, em 1985, sobre a maneira como a ideologia da sexualidade, do erótico, poderia influir tanto na epidemiologia da AIDS como nas políticas de prevenção. Voltei então para o Brasil, por um curto período, para pesquisar especificamente essas questões. Foi esse trabalho que resultou no primeiro artigo acadêmico que publiquei, na revista Medical Anthropology Quarterly 7, que veio a ser o primeiro artigo antropológico sobre AIDS publicado numa revista indexada. Em 1988, terminei o doutorado e resolvi voltar para o Brasil e fazer uma pesquisa mais profunda sobre a política de AIDS. Esse período, que a princípio ia ser de um ano, prolongou-se por mais dois e acabou se estendendo por dez anos. Há também uma segunda dimensão, de ordem pessoal, que faz parte da vida de todos nós, na qual vão se construindo relações afetivas e amorosas, amizades, que ultrapassam a esfera profissional. Permanecer no Brasil foi, além de uma decisão intelectual, também uma decisão pessoal. De repente percebi que as pessoas mais importantes para mim estavam aqui e que fazia muito mais sentido tentar construir uma vida no Brasil do que em qualquer outro lugar. Eu poderia contar essa mesma história do ponto de vista estritamente intelectual, mas isso, de certa forma, seria desonesto, porque de fato não foi assim que ocorreu. Foi uma história como a vida - e todas as suas dimensões - o fundamental na decisão tomada. O que, em última instância, significa fazer com que o trabalho ganhe sentido no contexto da vida e viceversa. Para mim, também esse encontro com a sexualidade como área de estudo tinha muito a ver com isso. Para qualquer pessoa que investigue sexualidade, raça, gênero, ou qualquer outro fenômeno que, de uma forma ou de outra, esteja relacionado com as dimensões mais pessoais da identidade e da subjetividade, existe sempre uma negociação entre quem você é e como vai construir seu próprio campo de investigação. Isso não significa confundir uma coisa com a outra - você pode, por exemplo, ser branco e investigar as relações raciais, a discriminação dos negros -, mas quer dizer que, de alguma forma, a sua vida pessoal está implica- da no seu projeto de pesquisa. Em outros campos que não estejam relacionados com a construção da identidade, talvez essa implicação seja menor, menos problemática, ou requeira menos negociação. Na investigação de sexualidade, gênero ou raça, essas questões passam sempre por um viés pessoal, que tem de ser administrado, pensado e interpretado.

RB No Brasil e mesmo internacionalmente você tem sido uma pessoa fundamental, pela sua atuação profissional e sua obra para a legitimação do campo dos estudos de sexualidade. Que outros aspectos, além da AIDS, seriam relevantes para essa legitimidade e para a conformação desse campo?

RP A AIDS, certamente, é fundamental, assim como também são, de outra maneira, a saúde reprodutiva e o campo de estudos de população. Especialmente a partir dos anos 90, esses dois campos que emergiram separadamente população e saúde reprodutiva, de um lado, e a AIDS, a sexualidade e homossexualidade, de outro - passaram a convergir e a interagir. A AIDS surgiu como uma epidemia, como uma questão que precisava de uma resposta urgente, o que conferiu legitimidade ao estudo da sexualidade. E também, por falta de dados, não se podia pensar sobre a AIDS, em 1985, sem encarar o fato de que se sabia muito pouco sobre a sexualidade. Além disso, a epidemia de AIDS tornou mais evidente a diversidade sexual, dentro de cada sociedade e através das sociedades. Até então, a sexualidade era pensada de uma maneira biológica ou psicológica, mas fundamentalmente como sendo universal, a mesma para todo o mundo. Mas as profundas diferenças na dinâmica da epidemia de AIDS em culturas da África subsaariana, em comunidades gays, nos países da Europa Ocidental ou na América do Norte - chamavam a atenção não só para a sexualidade em si, mas para a diversidade sexual e a sua complexidade. Nesse sentido, a epidemia provavelmente ajudou tanto a priorizar o campo como merecedor de investimento e reflexão, bem como a trazer a preocupação com a construção social da sexualidade. Esses temas entraram forçosamente na pauta de discussão até nos setores a princípio mais resistentes, como entre os profissionais da área médica. De repente, abriram-se os olhos, admitindo-se que se sabia muito pouco e que havia muito a ser investigado, o que não quer dizer que tenha sido fácil. Foi uma luta! Lembro-me de quando participei da construção do primeiro programa global de controle da AIDS na OMS, em 1988, 1989 e 1990, sob a direção de Jonathan Mann. Ele conseguiu que a OMS 
apoiasse as investigações sobre sexualidade, mas a pesquisa ainda era tímida, realmente não se queria enfrentar o tema da sexualidade. Foi uma luta a constituição dessa agenda, até entre setores razoavelmente esclarecidos. Nesse sentido, o meu trabalho, bem como o de outras pessoas daquela época, foi realmente fundamental. Outro produto disso foi o despertar para a relevância do tema por parte de algumas fontes de financiamento, por meio de fundações privadas, entre as quais se destacam a Fundação Ford e, mais tarde, as fundações MacArthur e Rockefeller.

RB Quer dizer que você confere, nesse sentido, um grande crédito às agências de fomento nãogovernamentais?

RP Em um primeiro momento, sim. A relação entre agências não-governamentais e agências intergovernamentais é sempre complicada. Normalmente, é típico das pequenas agências nãogovernamentais apoiar as áreas de maior risco, mas investindo poucos recursos. E se os resultados são interessantes, a tendência é que essas áreas sejam incorporadas na agenda das agências intergovernamentais, que possuem maiores recursos. No campo da sexualidade, ocorreu esse processo: as fundações privadas fizeram uma primeira aposta, depois essa questão foi incorporada, com recursos mais pesados, pelas agências maiores, governamentais e intergovernamentais.

RB Você diria que esse processo também ocorre em países como o Brasil? Isso me parece mais claro em países como os Estados Unidos, onde há verbas substantivas para pesquisa.

RP No caso da AIDS, por causa da particularidade do Brasil - um país grande, com uma população significativa, uma economia importante no sistema global -, há recursos vindos de agências intergovernamentais, como o Banco Mundial, mais do que em outros países em desenvolvimento. Basta citar o investimento feito para realizar uma primeira pesquisa nacional sobre comportamento sexual 8 e agora para uma segunda rodada da mesma pesquisa. Uma fundação dificilmente poderia fazer esse tipo de investimento. É muito mais complicado. De certa forma, é interessante comparar com a situação dos Estados Unidos, onde havia uma pesquisa nacional pronta para ser feita com recursos governamentais, que foi cortada por conservadorismo político no final dos anos 80 e início dos 90, e levada adiante pelas fundações, embora com menor abrangência 9. Estou me referindo à pesquisa da Universidade de Chicago, de Edward Laumann e colaborado- res 10 (1994), que foi finalmente publicada pela University of Chicago Press sob o título The Social Organization of Sexuality: Sexual Practices in the United States.

RB O Relatório Hite 11 é anterior a isso.

RP É muito anterior e não científico, no sentido da amostragem 12 . Nos anos 80 , o projeto de pesquisa da Universidade de Chicago foi derrubado pelos republicanos no senado dos Estados Unidos. Ia ser o primeiro estudo sobre o tema e, ao contrário do Relatório Hite 11, muito mais rigoroso em seus procedimentos metodológicos, com uma amostra representativa em termos estatísticos 13. As fundações tiveram de entrar para garantir sua realização. Aqui, as pesquisas começaram, mas de fato os projetos foram encampados em nível governamental somente no campo da AIDS e por causa da existência dessa verba, que era muito maior que em outros campos. Entretanto, no Brasil, temse assistido à incorporação desse tema como prioridade governamental no MS, mas não em agências nacionais de fomento a pesquisas, como o Conselho Nacional de Desenvolvimento Científico e Tecnológico (CNPq). Nesse sentido, você tem toda razão: nos Estados Unidos, com estrutura e verbas substanciais para pesquisa, apesar de todos os problemas políticos que existem hoje em dia, ainda assim há o apoio governamental. Por exemplo, no departamento que atualmente chefio, na Universidade de Colúmbia, uma das primeiras coisas que fiz foi criar um centro de estudos sobre gênero, sexualidade e saúde, de certa forma inspirado no modelo do que fizemos na UERJ, no Programa de Gênero, Sexualidade e Saúde. Nós conseguimos dois financiamentos iniciais da Fundação Ford para começar a desenvolver projetos. Agora estamos na fase de elaboração de um projeto de treinamento, incluindo a concessão de bolsas para os alunos, que deve ser financiado com recursos governamentais. A lógica é essa: tem-se uma pequena verba não-governamental que dá a possibilidade de inovar, fazer um investimento de risco, mas mostrar que é um campo em que vale a pena investir, e aí, com alguma sorte, consegue-se verba governamental para dar prosseguimento a essa linha de pesquisa.

RB Penso que essa é uma grande diferença, pois as possibilidades de financiamento no Brasil não seguem usualmente esse caminho. Dando continuidade aos temas que concebemos para essa entrevista, gostaríamos que você falasse um pouco sobre as diferentes perspectivas teóricas que enfocam o tema da sexualidade e como você se localiza nesse campo. 
RP Nos anos 80 , havia uma polarização muito grande entre o essencialismo e o construtivismo 2 . De um lado, tinha-se a visão da sexualidade como um produto dado pela natureza, seja pela biologia ou pela psicologia, e, de outro, entendida como cultural, social e historicamente construída e, portanto, variável em diferentes momentos históricos e contextos sociais. Em parte como resultado das pesquisas sobre HIV/AIDS nos anos 80 e ao longo dos anos 90 , houve o surgimento de uma terceira posição que tenta escapar a essa polarização. É denominada por alguns de biopsicossocial, perspectiva que tenta integrar as duas primeiras vertentes. Eu arriscaria dizer que um estudo entre os pesquisadores que trabalham no campo provavelmente revelaria que a maioria deles se posiciona nessa vertente biopsicossocial, que talvez venha apresentando menos avanços em termos teóricos. Constatam-se maiores avanços nas posições mais radicais, seja na genética, representativa do lado essencialista por exemplo, na tentativa de vincular certas práticas e identidades a uma dada construção genética, enfim, o gene dos gays -, ou no construtivismo mais radical. Esses projetos, de fato, têm avançado mais em termos de propiciar pesquisas interessantes. Esse processo, me parece, coloca duas questões importantes. Uma delas mostra claramente que, até hoje, apesar de todo o investimento no campo da sexualidade, ainda falta investimento financeiro substantivo, investimento de longo prazo no que eu chamaria de investigações de fundo. Ou seja, em outros campos científicos, o que embasa a pesquisa aplicada, pelo menos em países desenvolvidos, resulta de investimentos em áreas básicas como a física, a química etc. Os investimentos não vão produzir necessariamente alguma conseqüência prática, aplicada e imediata, mas o dinheiro continua sendo investido porque as pessoas sabem que isso cria fundamentos que depois possibilitarão pesquisas aplicadas. Na sexualidade esse processo não aconteceu. A AIDS desmascarou isso, mas até hoje quase não há centros de pesquisa em nenhum lugar do mundo sobre os quais realmente se possa dizer: esse é um centro de pesquisa sobre sexualidade - exceto o Instituto Kinsey, mas sem o mesmo vigor de antes. Um dos grandes desafios que estamos pensando na Universidade de Colúmbia é a criação de espaços em algumas instituições de peso para possibilitar essa tarefa, que não será nada fácil... A segunda questão se refere ao fato de as pesquisas construtivistas terem tido uma aplicabilidade muito imediata, muito relevante no contexto da AIDS, uma das razões pelas quais realmente ti- veram algum sucesso. Na medida em que se podia entender melhor a construção social da homossexualidade e das práticas sexuais, houve um desdobramento em projetos de prevenção, ações de reeducação e em estratégias de comunicação. Havia uma passagem muito rápida dessa abordagem mais construtivista para uma aplicabilidade prática, programática. No Brasil, certamente, uma das coisas que me impressionaram, muito mais até do que nos Estados Unidos, foi a abertura que os programas governamentais, oficiais, tinham para esse tipo de abordagem interpretativa. Houve o diálogo desde o começo, logo na primeira fase do Programa Nacional de AIDS no Brasil, quando Lair Guerra de Macedo era a coordenadora, ainda nos anos 80 14. Até quando nós, ativistas, criticávamos as políticas adotadas pelo governo, ainda assim havia o diálogo e uma abertura para entender as particularidades da construção cultural da sexualidade.

RB Parece-me que um outro investimento a ser feito seria na abordagem inter ou transdisciplinar da sexualidade, um esforço que, de fato, ainda não se completou.

RP Concordo. Há espaços onde isso tem acontecido mais do que em outros. Num primeiro instante, a idéia de construções culturais foi muito enfatizada. Foi um momento no qual a contribuição da Antropologia foi fundamental. Mas, ao longo dos anos 90, houve um crescente interesse pelas questões mais estruturais da epidemia, trazendo, por exemplo, a contribuição da Sociologia e do estudo das desigualdades sociais. Somaram-se ainda contribuições da Ciência Política, da Economia Política, em um esforço interdisciplinar que uniu a Antropologia, a Sociologia e os Estudos Políticos e Econômicos no enfoque da economia política do corpo. Essa é uma área em que de fato a interdisciplinaridade tem crescido bastante, mas ainda assim sem envolvimento de psicólogos, de pessoas ligadas às ciências comportamentais. A verdadeira interdisciplinaridade só se consegue no trabalho conjunto de montagem e desenvolvimento de projetos de pesquisa. E, ironicamente, as próprias estruturas que fomentam pesquisas, o financiamento às pesquisas, a organização da universidade impedem, de algum modo, que isso aconteça, porque tudo continua sendo estruturado de uma maneira disciplinar e, de certa forma, ultrapassada. Há alguns espaços nos quais existe uma certa interdisciplinaridade, o que é típico no campo da saúde coletiva, por exemplo. Em vários centros há departamentos que agregam sociólogos, antropólogos, cientistas políticos, psiquia- 
tras, psicanalistas, mas realmente, conseguir que pessoas desses diferentes âmbitos trabalhem juntas não é fácil. Muitas vezes, o que passa por interdisciplinaridade é um leque de projetos feitos em comum, mas cada qual com seu olhar disciplinar.

RB Caminhando para a questão da AIDS, você vem insistindo desde a década de 80 sobre a necessidade da interlocução entre academia, sociedade e Estado e o papel fundamental desse diálogo para alcançar alguma resposta efetiva no controle da AIDS.

RP O primeiro dos grandes achados foi a descoberta das dimensões sociais e políticas da epidemia de AIDS, que surgiu da sociedade e não da academia. Até mesmo as respostas à epidemia, como o primeiro enfrentamento efetivo na comunidade homossexual norte-americana, surgiram da própria comunidade. Não partiram de programas governamentais e, muito menos, de investigadores. Estes tiveram de aprender com essas lições para trazê-las para uma ótica científica e começar a investigar. Aos poucos, em alguns lugares, como nitidamente ocorreu no Brasil, os governos foram suficientemente esclarecidos para aprender com essas experiências. Olhando para os anos 80, algumas pessoas, como Herbert Daniel ou o Betinho 15 , tiveram capacidade de desvendar a epidemia com mais clareza sociológica, antropológica e política do que os investigadores na universidade. Aos poucos, por causa da pressão dos movimentos sociais, houve um diálogo envolvendo o Estado, o que acabou possibilitando uma abordagem menos técnica, um pouco mais politizada 14 . Nesse sentido, a AIDS é só um exemplo a ser seguido em outros campos. Não foi só um diálogo de pessoas em lugares estanques; havia um trânsito delas em várias esferas, como foi o meu caso. Eu era professor universitário, comecei a atuar no Conselho da ABIA, assessorando o trabalho de uma ONG; passei um tempo como chefe da Unidade de Prevenção do Programa Nacional de AIDS; depois passei a diretor executivo da ABIA, quando o Herbert Daniel esteve afastado por questões de saúde, e durante todo o tempo mantive minha ligação, como professor universitário, com o IMS da UERJ. Parece-me que isso foi muito positivo para o crescimento e o amadurecimento do trabalho. Quando as pessoas das ONGs passam a assumir responsabilidades em postos do Estado, começam a amadurecer e a ter uma visão um pouco mais complexa dos desafios e dificuldades, de modo a propiciar uma contribuição eficaz para a melhoria do trabalho. Isso ocorreu de uma manei- ra muito intensa com relação à AIDS, embora tenha abrangido o setor saúde como um todo. O pessoal do Instituto de Medicina Social e o da Fundação Oswaldo Cruz (FIOCRUZ), por exemplo, estava sempre indo e vindo para ocupar postos na esfera executiva do governo. Em São Paulo havia um movimento quase dialético, que me parece ter sido muito positivo para o campo da saúde no Brasil. Depois da ditadura militar, quando o pessoal da reforma sanitária voltou a ocupar cargos públicos importantes, houve uma melhora da qualidade do trabalho na saúde coletiva, do qual a AIDS é só um exemplo muito intenso - e talvez um exemplo que valha a pena entender um pouco melhor, porque a epidemia trouxe novos atores, conferiu espaços de legitimidade para o movimento gay e lésbico, para o movimento feminista, de uma maneira diferente do que tinha havido até então. A AIDS trouxe algumas coisas novas.

RB No caso brasileiro, você tem uma clara percepção da importância da relação entre academia, sociedade e Estado. Que semelhanças e diferenças existem com a realidade norte-americana?

RP Nos Estados Unidos, os campos são mais amplos e os recursos em jogo são maiores, portanto, parte dos diálogos se dá de uma maneira mais complexa. Não ajuda em nada, por exemplo, o campo político norte-americano ter, de um lado, uma democracia mais estabelecida e, de outro, contar com um jogo partidário no qual a diferença entre republicanos e democratas é muito pequena. O que não deixa de ser irônico. Mas, em termos de grandes tendências, os contextos de Brasil e Estados Unidos são semelhantes. No governo Clinton, por exemplo, havia um intercâmbio muito grande entre academia, sociedade civil e Estado. Isso era muito nítido na Conferência Internacional de População e Desenvolvimento, realizada pela Organização das Nações Unidas (ONU), em 1994, no Cairo, ou em outros processos semelhantes, que se deram de uma maneira muito parecida com o que estava ocorrendo no Brasil no mesmo período. Nos períodos de governo republicano, essa relação torna-se muito complicada, especialmente tratando-se de AIDS e sexualidade, educação sexual e população, campos extremamente marcados por questões ideológicas, as quais são muito contestadas nos Estados Unidos por causa de sua tradição puritana e conservadorismo acentuado. No governo atual, por exemplo, há uma polarização crescente, em que a sociedade civil e a academia ficam completamente afastadas do Estado. E este é 
tomado, basicamente, por representantes de "think tanks" 16, conservadores e religiosos que usam seus recursos, que são muitos, para alocar no Estado “cientistas" que tenham posturas ideológicas extremistas e conservadoras. Parece-me que, apesar de o Brasil ser uma sociedade extremamente religiosa, as religiões brasileiras, inclusive a católica, colocam-se de forma menos problemática. Com o movimento evangélico isso é mais complicado, pois há políticos evangélicos, a bancada evangélica, o que torna a situação um pouco mais parecida, lamentavelmente, com a norte-americana.

RB Convivendo nos dois contextos acadêmicos, no Brasil e nos Estados Unidos, quais seriam as principais diferenças e semelhanças existentes e de que maneira estas interferem na produção do conhecimento?

RP Existem grandes semelhanças e grandes diferenças. Usando o exemplo do IMS da UERJ, o espaço institucional é muito semelhante ao da Escola da Saúde Pública de Colúmbia. Embora esta última seja muito maior, com mais quadros acadêmicos, a estrutura de departamentos não é muito diferente. Há o mesmo leque disciplinar; historiadores, psicólogos, sociólogos, antropólogos e a tentativa de criar esse espaço de reflexão interdisciplinar, aplicando as teorias e metodologias das Ciências Sociais às questões fundamentais da Saúde Pública. Então, nesse sentido, a proposta institucional é muito parecida. É óbvio que, em termos de recursos, a escassez no Brasil prejudica muito. Nos Estados Unidos, principalmente em Colúmbia, os recursos estão muito mais disponíveis do que aqui. Há também uma outra diferença: Colúmbia é uma universidade privada, não tem dinheiro do Estado, tem de levantar todos os recursos, e a educação oferecida aos alunos, a formação, é distinta por ser uma universidade privada. Nas universidades brasileiras, principalmente nas públicas, tem-se maior clareza sobre sua responsabilidade social - mais clareza, mas, ao mesmo tempo, menos capacidade de desempenhá-la, pela escassez de recursos. A diferença se faz ainda mais nítida, pois, especialmente ao longo dos anos 90, ao que me parece, houve sistematicamente menos investimentos nas universidades brasileiras, tanto federais como estaduais, ao passo que nos Estados Unidos, em Colúmbia, pelo menos nos últimos seis ou sete anos o orçamento da Escola de Saúde Pública passou de 30 para mais de 100 milhões. Em menos de uma década triplicaram-se os recursos disponíveis, o que dá uma sensação de que as coisas estão acontecendo, crescendo, com novidades sendo im- plementadas. É um ambiente muito excitante, muito estimulante para trabalhar. As pessoas sentem isso, muitas trabalham até à meia-noite ou chegam para trabalhar às sete, oito horas da manhã, estimuladas para fazer o que estão fazendo. Entretanto, a proposta intelectual não é muito diferente, o que me impressionou. Eu diria que muitas coisas que aprendi no Brasil foram implementadas no meu trabalho nos Estados Unidos de uma maneira interessante. Se eu não tivesse desenvolvido um trabalho teórico, intelectual, dificilmente seria julgado favoravelmente por lá, mas a dimensão mais política do meu estudo tem sido uma coisa interessante.

RB Você acha que o reconhecimento da interseção entre ativismo e academia como algo importante nos Estados Unidos é recente?

RP É mais recente, e acho também que não é típico em todos os campos. A Saúde Coletiva, bem como o Serviço Social, são campos que lidam sempre com problemas sociais, e a relevância ou não do trabalho depende, de certa forma, da capacidade de se engajar e dialogar politicamente. Isso é diferente de uma certa "torre de marfim" em que eu talvez estivesse se fosse professor em um departamento de Antropologia. Talvez não fosse tão valorizado quanto num departamento de Ciências Sociomédicas, por exemplo. Há também aqui uma certa especificidade da Universidade de Colúmbia. Lá, dentro da Saúde Pública, que tradicionalmente tem sido um espaço mais de esquerda, quase todos os professores mais engajados são antigos e de alguma forma vinculados com as esquerdas. Há um contraste muito grande com as universidades de Harvard e Johns Hopkins, altamente competitivas, mais tecnocrata no caso desta última e mais conservadora no contexto da primeira.

RB Você tem exatos vinte anos de Brasil. Após esse tempo, que impacto você diria que teve na sua vida profissional o fato de ter vindo, ter ficado aqui e ter mantido intercâmbio de diversas maneiras com o Brasil?

RP Não posso imaginar minha vida profissional sem isso, tampouco a minha vida pessoal. Minha visão de mundo foi profundamente formada pelo meu encontro com a sociedade brasileira e, espero eu, de uma maneira muito positiva. O que aprendi no Brasil, às vezes com pesquisadores, mas muitas vezes com pessoas como Herbert Daniel, Betinho ou colegas de trabalho no campo da AIDS, tem sido muito mais importante do que qualquer formação educacional que tive anteriormente e decerto 
influenciou o tipo de problema, o tipo de questão que eu investigo hoje, ou com o que sou movido a me preocupar. Isso tudo foi fundamentalmente formado no encontro com o Brasil e as questões em debate aqui. A migração que fiz, ao longo dos anos, de uma perspectiva mais estritamente antropológica - preocupado com a cultura - para uma preocupação maior com questões políticas, com a economia política, foi inteiramente movida e estruturada pelo encontro com o trabalho no Brasil e o meu envolvimento com pesquisadores e pensadores nesse campo. Muito do que estou fazendo nos Estados Unidos, em Colúmbia, é tentar levar algumas experiências e lições construídas aqui no Brasil. Um grande mal dos norte-americanos é que eles não aprendem nada com o resto do mundo. Se o trabalho que eu estou fazendo lá tem uma pequena utilidade, é por tentar inverter isso, construir um centro de pesquisa baseado fundamentalmente no programa que nós construímos aqui, tentar trazer algumas questões mais políticas para descentralizar a visão de lá e relativizar outras. Isso pode dar, espero eu, alguns resultados interessantes.

RB Quais são os desafios que se colocam para você hoje, trabalhando nesses dois ambientes acadêmicos distintos? Um deles, você acabou de mencionar. Há outros?

RP Esse, certamente, é um dos principais. Um segundo desafio é uma questão da conjuntura política num mundo globalizado, o que é uma outra coisa. Ao longo desses vinte anos, de certa forma, as questões colocadas nos dois países acabam por ser mais parecidas por conta das mudanças no capitalismo global - mudanças que aproximam o chamado "primeiro mundo" do chamado "terceiro mundo", ao mesmo tempo que criam um "quarto mundo" nas comunidades pobres e excluídas tanto no Norte quanto no Sul. A marginalização de certos setores da população, tanto lá como aqui, parece ser muito semelhante hoje, talvez mais do que há vinte anos. Estamos num momento político muito ruim. O governo Bush é uma tragédia mundial. $\mathrm{O}$ ataque terrorista de 11 de setembro teve, a médio prazo, a sua pior conseqüência: legitimou o governo Bush. Um governo que estava a caminho de cair por si mesmo, sem legitimidade nos Estados Unidos e que certamente não seria reeleito, virou um governo forte. Aquele ataque produziu um efeito típico: em momentos de ameaça os americanos se unem e investem de legitimidade as suas lideranças. Agora fica difícil imaginar o Bush não sendo reeleito e fazendo uma presidência de oito anos. É um momento ruim e suas conseqüências também são muito ruins. Muito mais do que nos anos 80, os Estados Unidos têm uma hegemonia global absoluta, sem nenhuma oposição, que terá efeitos na área de população, da saúde e dos direitos reprodutivos e da própria AIDS. O governo vai condicionar a concessão de dinheiro para a AIDS à promoção de abstinência sexual. Nesse contexto, acho até que eu estou bem posicionado, em dois sentidos: pelo trabalho no Brasil, que tem liderado uma política progressista dessas questões com relação aos países menos ricos, e nos Estados Unidos, pelo menos, tenho a felicidade de estar numa Universidade que se constitui como pólo de resistência. Colúmbia certamente é uma aldeia para os "refugiados" que vêm do governo Clinton quando a administração do Bush entra. É um papel bastante importante a ser desempenhado, em termos de resistência, mas reconhecendo que a batalha vai ser longa, que somos minoria e muito enfraquecidos ante o dragão que estamos enfrentando.

RB Para finalizar, o que você enxerga como prioridades, hoje, na área de pesquisa sobre sexualidade? O que ainda falta fazer, onde se deve investir?

RP Tanto no Brasil quanto nos Estados Unidos, um dos grandes desafios é a institucionalização. Muito tem sido feito por conta da AIDS e em nome da sexualidade em si, mas com recursos que se evaporam muito fácil e rapidamente se o trabalho não for mais institucionalizado. Seria muito importante a criação de espaços institucionais capazes de treinar, formar quadros e incorporá-los em trabalhos fixos, que não sejam precários. Institucionalmente, o trabalho ainda é muito precário. Nós temos de entrar numa nova fase. Mas o grande problema e volto para aquele desafio anteriormente apontado - é o momento histórico muito ruim para fazê-lo. Justamente por isso, vejo como questão prioritária, mais do que qualquer questão intelectual em si, como é que podemos construir, de uma forma mais sólida, as bases para desenvolver esse trabalho a longo prazo. E, nesse sentido, penso que o Programa de Metodologia em Pesquisa que vocês coordenam é um exemplo necessário para construir e consolidar esse campo de investigação. Um próximo passo é ver esse tipo de programa incorporado no currículo normal, não ser só um projeto especial. Isso sempre foi pensado como uma próxima etapa depois desse primeiro momento. Nesse sentido, ele está indo na direção certa e, me parece, até com mais sucesso do que talvez imaginássemos quando tivemos a primeira idéia. Finalmente, acho fundamental chamar a 
atenção também para o aspecto positivo da colaboração interinstitucional que esse programa proporciona, ainda que às vezes seja difícil sustentar na prática a consolidação de todos os interesses envolvidos, por ser algo que ultrapassa os espaços institucionais.

\section{Referências e notas}

1 Esta entrevista foi concebida e editada pelas autoras e realizada em duas etapas por Regina Maria Barbosa, no Rio de Janeiro em março de 2003 e em Nova York em setembro do mesmo ano.

2 PARKER, R., 1991. Corpos, Prazeres e Paixões: Cultura Sexual no Brasil Contemporâneo. São Paulo: Best Seller.

3 PARKER, R., 2000. Na Contramão da AIDS: Sexualidade, Intervenção, Política. Rio de Janeiro: Associação Brasileira Interdisciplinar de AIDS/São Paulo: Editora 34

4 PARKER, R., 2002. Abaixo do Equador: Culturas de Desejo, Homossexualidade Masculina e Comunidade Gay no Brasil. Rio de Janeiro: Record.

5 A Passarela Prof. Darcy Ribeiro, também conhecida como Sambródomo, está localizada na Rua Marquês de Sapucaí, no bairro de Cidade Nova, no Rio de Janeiro. Durante o Carnaval, anualmente, nela ocorre o desfile oficial de Escolas de Samba, agremiações que apresentam enredos por meio do samba, da fantasia e dos carros alegóricos.

6 A esse respeito ver: CASTILHO, E. A.; CHEQUER, P. \& STRUCHINER, C. J., 1992. AIDS no Brasil. Informe Epidemiológico do SUS, 1:117-124.

7 PARKER, R., 1987. Acquired immunodeficiency syndrome in urban Brazil. Medical Anthropology Quarterly, 1:155-172.

8 MS (Ministério da Saúde), 2000. Comportamento Sexual da População Brasileira e Percepções do HIVIAIDS. Brasília: Coordenação Nacional de DST e AIDS, Secretaria de Políticas de Saúde, Ministério da Saúde.

9 A esse respeito ver o capítulo 9 (pp. 176-208) em: ERICKSEN, J. A. \& STEFFEN, S. A., 1999. Kiss and Tell: Surveying Sex in the Twentieth Century. Cambridge: Harvard University Press.
10 LAUMANN, E. O.; GAGNON, J. H.; MICHAEL, R. T. \& MICHAELS, S., 1994. The Social Organization of Sexuality: Sexual Practices in the United States. Chicago: University of Chicago Press.

11 HITE, S., 1978. O Relatório Hite: Estudo sobre a Sexualidade Feminina. Rio de Janeiro: Bertrand Brasil.

12 The Hite Report: A Nationwide Study of Female Sexuality, publicado pela feminista Shere Hite em 1976, provocou grande impacto à época por contestar numerosas noções estabelecidas sobre a sexualidade feminina, mas, no entanto, é criticado atualmente por suas fragilidades metodológicas, especialmente quanto à representatividade dos achados.

13 Apesar de técnicas de amostragem probabilística terem sido desenvolvidas e incorporadas aos inquéritos populacionais desde as décadas de $30 \mathrm{e}$ 40 do século XX, até a década de 70 , acreditava-se ser impossível adotá-las em pesquisas sobre sexualidade, pelo caráter íntimo e privado das respostas que ocasionaria um alto percentual de recusas. A partir dos anos 80 , inúmeros estudos foram realizados, utilizando amostras probabilísticas, comprovando sua viabilidade - a esse respeito ver o capítulo 1 (pp. 7-13) em: ERICKSEN, J. A. \& STEFFEN, S. A., 1999. Kiss and Tell: Surveying Sex in the Twentieth Century. Cambridge: Harvard University Press.

14 PARKER, R., 1994. A Construção da Solidariedade: AIDS, Sexualidade e Política no Brasil. Rio de Janeiro: Relume-Dumará.

15 Ambos fundadores da ABIA, militantes dos direitos de portadores de HIV e doentes de AIDS.

16 Em termos gerais, "think tanks" poderia ser traduzido como instância, institucionalizada ou não, de produção intelectual de ponta. Neste contexto refere-se especificamente à produção intelectual de conservadores ligados ao atual governo americano. 